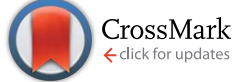

Cite this: RSC Adv., 2016, 6, 3608

Received 4th November 2015

Accepted 23rd December 2015

DOI: $10.1039 / \mathrm{c} 5 \mathrm{ra} 23214 \mathrm{~g}$

www.rsc.org/advances

\title{
Polyacrylonitrile (PAN)/crown ether composite nanofibers for the selective adsorption of cations
}

\begin{abstract}
Sinem Tas, ${ }^{a}$ Ozge Kaynan, ${ }^{\mathrm{b}}$ Elif Ozden-Yenigun ${ }^{\mathrm{b}}$ and Kitty Nijmeijer ${ }^{\star a}$
In this study, we prepared electrospun polyacrylonitrile (PAN) nanofibers functionalized with dibenzo-18crown-6 (DB18C6) crown ether and showed the potential of these fibers for the selective recovery of $\mathrm{K}^{+}$ from other both mono- and divalent ions in aqueous solutions. Nanofibers were characterized by SEM, FTIR and TGA. SEM results showed that the crown ether addition resulted in thicker nanofibers and higher mean fiber diameters, in a range of 138 to $270 \mathrm{~nm}$. Batch adsorption experiments were conducted in order to evaluate the potential of the crown ether modified nanofibers as an adsorbent for ion removal. The maximum adsorption capacity of the crown ether modified nanofibers for $\mathrm{K}^{+}$was 0.37 mmol g${ }^{-1}$ and the nanofibers followed the selectivity sequence of $\mathrm{K}^{+}>\mathrm{Ba}^{2+}>\mathrm{Na}^{+} \sim \mathrm{Li}^{+}$for single ion experiments. Adsorption of $\mathrm{Ba}^{2+}$ ions onto crown ether-modified nanofiber was examined by XPS and the results confirmed the adsorption of the ion. Mixed ion adsorption experiments revealed competitive adsorption between $\mathrm{K}^{+}$and $\mathrm{Ba}^{2+}$ ions for the available binding sites. This effect was not observed for the other monovalent ions present in the solution and exceptionally high selectivities for $\mathrm{K}^{+}$over $\mathrm{Li}^{+}$and $\mathrm{Na}^{+}$ were obtained. Also the crown ether modified nanofibers exhibited good regeneration properties and a good reusability over multiple consecutive adsorption-desorption cycles. Electrospinning is thus shown to be a very versatile tool to prepare crown ether functional polymer adsorbents for the selective recovery of ions.
\end{abstract}

\section{Introduction}

Electrospinning is a versatile and powerful technique for nanofiber formation from a wide variety of polymers such as water soluble polymers, biopolymers and liquid crystalline polymers. ${ }^{1-4}$ In this technique, electrical forces are applied to produce polymer fibers with diameters ranging from a few nanometers to several micrometers. ${ }^{5}$ Electrospun nanofibers feature a high surface area-to-volume, high porosity and flexibility for chemical/physical functionalization..$^{1,5}$ Moreover, consistent production of nanofibers allows their application in various filtration applications ${ }^{6-8}$ as fuel cell membranes, ${ }^{9,10}$ for drug delivery ${ }^{11}$ and as protective textiles..$^{12,13}$

The high surface area to volume ratio, porosity, and mechanical integrity of electrospun fibrous materials make them attractive alternatives to conventional adsorbents. A potentially attractive functionalization to increase the selectivity of the nanofibers includes their macrocycle functionalization. A macrocycle is a cyclic macromolecule or a macromolecular cyclic portion of a molecule. Such macrocycle functionalized fibers can serve as an adsorbent in water treatment owing to the

${ }^{a}$ Membrane Science \& Technology, Mesa ${ }^{+}$Institute for Nanotechnology, University of Twente, P.O. Box 217, 7500 AE Enschede, The Netherlands.E-mail: d.c.nijmeijer@ utwente.nl

${ }^{b}$ Istanbul Technical University, Faculty of Textile Technologies and Design, Department of Textile Engineering, 34437, Istanbul, Turkey selective binding ability of macrocycles with specific ions or organic molecules. Therefore, significant work on this topic has been performed and many researchers particularly focused on nanofiber modification with calixarenes and cyclodextrin. ${ }^{14}$ For example, nanofibers functionalized with calixarenes and cyclodextrins allow the removal of organic contaminants (e.g. Congo red, phenanthrene) from water. ${ }^{15-17}$ Another application of calixarene modified nanofibers is the selective adsorption of ions such as $\mathrm{La}^{3+}$ and $\mathrm{Cr}_{2} \mathrm{O}_{7}{ }^{2-}$ ions onto the nanofibers. ${ }^{18,19}$ Electrospun PAN nanofibers modified with $p$-sulfonatocalix[8]arene showed a maximum adsorption capacity of $155.1 \mathrm{mg} \mathrm{g}^{-1}$ and a selectivity for $\mathrm{La}^{3+}$ ion in the presence of $\mathrm{Fe}^{3+}, \mathrm{Al}^{3+}, \mathrm{Cu}^{2+}, \mathrm{Ca}^{2+}$, $\mathrm{Mg}^{2+}$ and $\mathrm{K}^{+}$ions. ${ }^{18}$

Following this line of reasoning, also electrospun nanofibers coupled with crown ethers could in principle also provide efficient platforms for selective metal ion removal. Crown ethers are well-known host molecules and have attracted increasing interest owing to their ability to form stable complexes with metal ions. ${ }^{20}$ Crown ethers possess negatively polarized oxygen atoms with variable cavity size. Therefore they can selectively bind various ions. ${ }^{21}$ This led to the design and synthesis of new crown ethers and various well-defined crown ether polymers. ${ }^{22-24}$ Owing to their high selectivities, considerable research interest has been devoted to the design of crown ether adsorbents as well. Duman et al. modified activated carbon cloth with mono and dibenzo derivatives of crown ethers. They 
investigated the adsorption behavior of $\mathrm{Cr}^{3+}, \mathrm{Co}^{2+}$ and $\mathrm{Ni}^{2+}$ ions onto crown ether modified activated carbon cloth. In this case, activated carbon cloth modified with benzo-18 crown- 6 exhibited the highest adsorption capacity of $0.22 \mathrm{mmol} \mathrm{g}^{-1}$ for the $\mathrm{Co}^{3+}$ ion. ${ }^{25}$ Eliseo et al. prepared crown ether immobilized carbon nanotubes as adsorbent for $\mathrm{Li}^{+}$ions. ${ }^{26}$ The dibenzo-14crown-4 modified carbon nanotube adsorbent showed a preference for cation uptake and followed the sequence of $\mathrm{Li}^{+}>\mathrm{Na}^{+}>$ $\mathrm{Mg}^{2+}>\mathrm{Ca}^{2+}, \mathrm{K}^{+} \sim \mathrm{Sr}^{2+}$. Jie et al. synthesized a crown ether incorporated thermoresponsive poly $(N$-isopropylacrylamide $)$ (PNIPAM) hydrogel. This hydrogel exhibits $\mathrm{Pb}^{2+}$ ion recognition and adsorption characteristics. The $\mathrm{Pb}^{2+}$ adsorption capacity of the hydrogel decreased from $142 \mathrm{mg} \mathrm{g}^{-1}$ to $112 \mathrm{mg} \mathrm{g}^{-1}$ when the temperature increased from $23{ }^{\circ} \mathrm{C}$ to $50{ }^{\circ} \mathrm{C} .{ }^{27}$ Crown ether incorporated ion-imprinted polymers were synthesized by many researchers as well. Those adsorbents have promising prospects in the selective recovery of $\mathrm{Li}^{+}, \mathrm{K}^{+}$and $\mathrm{Pb}^{2+}$ ions. ${ }^{28-30}$

In this work, we use the high selectivity of crown ethers towards specific ions and the versatility for functionalization and the high surface area to volume ratio of electrospun nanofibers. To the best our knowledge, for the first time, we introduce the concept of crown ether/polyacrylonitrile (PAN) nanofibers for the selective binding of monovalent ions from aqueous solutions. PAN was chosen as polymer for the electrospinning process because of two reasons. Firstly, PAN membranes have been widely used in aqueous filtration applications. ${ }^{31,32}$ Secondly, PAN is a well-known carbon fiber precursor due its easy conversion into carbon fibers, its high carbon yields and its cost effective processing. ${ }^{33,34}$ In this regard, we prepared PAN nanofiber mats with different loading ratios of crown ether. We investigated the effect of crown ether loading and contact time on the adsorption capacity of functionalized nanofiber mats for both single and mixed ion solutions of $\mathrm{Li}^{+}, \mathrm{K}^{+}, \mathrm{Na}^{+}$and $\mathrm{Ba}^{2+}$ ions. We believe that the introduction of crown ethers enhances the operating window of electrospun nanofibers and will introduce specific ion selectivity, making them promising and more effective for adsorption and filtration applications.

\section{Experimental}

\section{Materials}

Dibenzo-18-crown-6 (DB18C6) (98\%), polyacrylonitrile (PAN, 99\% $\left.M_{\mathrm{w}} 150000\right)$ and $N, N$-dimethylformamide (DMF, 99.8\%) were obtained from Aldrich.

\section{Electrospinning}

8 wt\% PAN (Fig. 1a) powder was dissolved in DMF and mechanically stirred at room temperature for $24 \mathrm{~h}$. DB18C6 (Fig. 1b) was washed 3 times with $1 \mathrm{M} \mathrm{HCl}$ in deionized water at least 3 times and the purified crown ether was dried before use. Five DB18C6 concentrations $(0,5,10,15$ and 20 wt $\%)$ were selected. Homogeneous, stable suspensions were prepared and used for electrospinning. During spinning, the processing and ambient conditions were held constant during fiber formation. The electrospinning set up was positioned in a horizontal configuration, as shown in Fig. 2. The homogenous solutions were put in a $2 \mathrm{~mL}$ glass syringe kept with an 18 gauge metal
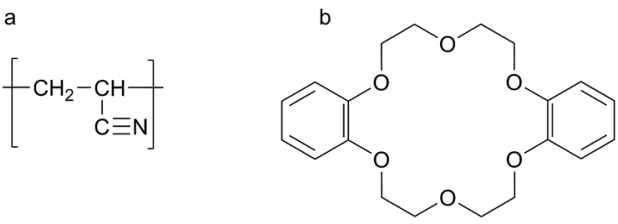

Fig. 1 Chemical structures of (a) PAN and (b) dibenzo-18-crown-6 (DB18C6).

needle. The syringe was placed horizontally positioned in a syringe pump. A high voltage power supply was connected to the needle tip. As ground electrode, a rotating drum covered with aluminum foil was used. The working distance between the needle tip and the rotating cylinder was $15 \mathrm{~cm}$. The cylinder rotated at $120 \mathrm{rpm}$. The flow rate of the solution was varied from $250 \mu \mathrm{L} \mathrm{h}^{-1}$ to $400 \mu \mathrm{L} \mathrm{h}^{-1}$. The electrospinning voltage was set to $15 \mathrm{kV}$. All electrospinning experiments were carried out at standard room temperature and relative humidity. Nanofibers were coded as PAN- $x$ where $x$ represents the weight percentage of DB18C6 with respect to PAN.

\section{Characterization}

The morphologies and mean diameters of the nanofibers were investigated by scanning electron microscopy (JEOL SEM JSM 6010 LA). Around 50 fibers were analyzed per sample and the mean fiber diameter (MFD) was determined from the scanning electron microscopy (SEM) images. Fourier transform infrared (FTIR) spectra were measured with a Bruker ALPHA. Thermogravimetric analysis (TGA) measurements were carried out using a Perkin Elmer TGA $4000.10 \mathrm{mg}$ of sample was heated under $\mathrm{N}_{2}$ atmosphere with a $20{ }^{\circ} \mathrm{C} \mathrm{min}^{-1}$ heating rate over a 50 to $800{ }^{\circ} \mathrm{C}$ temperature range. X-ray photoelectron spectroscopy (XPS) measurements were performed with a Quantera SXM with monochromatic $\mathrm{Al} \mathrm{K} \alpha$ as the excitation and an X-ray power of $50 \mathrm{~W}$.

\section{Single ion adsorption}

Batch single ion adsorption experiments were performed by adding $10 \mathrm{mg}$ of nanofibers in $10 \mathrm{~mL}$ of $10 \mathrm{mM}$ solutions of $\mathrm{KCl}$, $\mathrm{BaCl}_{2}, \mathrm{LiCl}$ and $\mathrm{NaCl}$ in ultrapure water. All adsorption tests were carried out at room temperature.

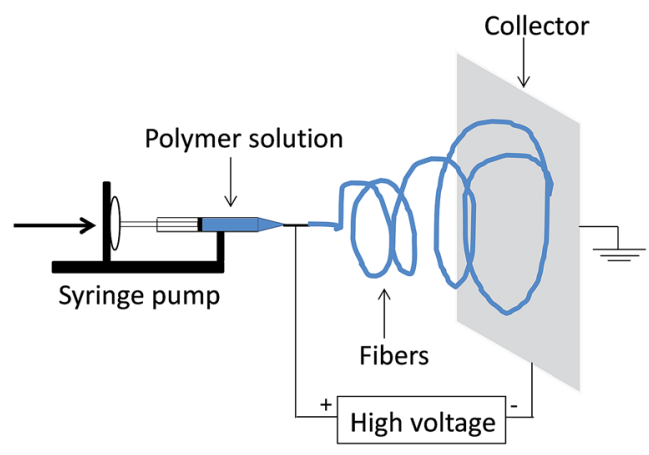

Fig. 2 Schematic representation of the electrospinning set-up. 
For analysis, $0.1 \mathrm{~mL}$ samples were taken at different time intervals. The samples were diluted and filtered with a $0.20 \mu \mathrm{m}$ filter (LLG, cellulose acetate (CA) syringe filter). The residual metal ions in the solution were analyzed using a BWB-XP flame photometer. The amount of metal ions adsorbed by the nanofibers was calculated from:

$$
q_{\mathrm{e}}=\frac{\left(C_{0}-C_{\mathrm{e}}\right) V}{m}
$$

where $q_{\mathrm{e}}$ is the adsorbed amount of metal ions per gram of nanofibers ( $\left.\mathrm{mmol} \mathrm{g}^{-1}\right), C_{0}$ and $C_{\mathrm{e}}$ are the initial and the equilibrium concentration ( $\mathrm{mM}$ ) of the specific cation in the solution, respectively. $V$ is the volume of the salt solution $(\mathrm{mL})$ and $m$ is the mass of the dry nanofibers $(\mathrm{g})$.

\section{Mixed ion adsorption}

In the case of the mixed ion adsorption experiments, the $10 \mathrm{mg}$ of nanofibers were left in contact with $10 \mathrm{~mL}$ of a mixture of 10 $\mathrm{mM} \mathrm{KCl}, 10 \mathrm{mM} \mathrm{BaCl}_{2}, 10 \mathrm{mM} \mathrm{LiCl}$ and $10 \mathrm{mM} \mathrm{NaCl}$ in ultrapure water for $24 \mathrm{~h}$. For analysis, $0.1 \mathrm{~mL}$ samples were taken after $24 \mathrm{~h}$. The samples were filtered over a $0.20 \mu \mathrm{m}$ filter (LLG, cellulose acetate (CA) syringe filter). The adsorption capacity for each ion was calculated using the eqn (1). The selectivity coefficient was subsequently calculated using eqn (2):

$$
S_{\mathrm{K}^{+} / \mathrm{C}^{+}}=\frac{q_{\mathrm{K}^{+}, 24}}{q_{\mathrm{C}^{+}, 24}}
$$

where $q_{\mathrm{K}^{+}, 24}$ and $q_{\mathrm{C}^{+}, 24}$ are the adsorption capacities $\left(\mathrm{mmol} \mathrm{g}^{-1}\right)$ of $\mathrm{K}^{+}$and other cations $\left(\mathrm{Li}^{+}, \mathrm{Na}^{+}\right.$or $\left.\mathrm{Ba}^{2+}\right)$ after $24 \mathrm{~h}$, respectively.

\section{Adsorbent regeneration}

Desorption experiments were carried out using a $1 \mathrm{M} \mathrm{HCl}$ solution in ultrapure water. The used PAN-10 nanofibers were placed in the $1 \mathrm{M} \mathrm{HCl}$ solution and magnetically stirred at 300 $\mathrm{rpm}$ at $25{ }^{\circ} \mathrm{C}$ for $48 \mathrm{~h}$. Then the nanofibers were washed with distilled water several times and dried at $60{ }^{\circ} \mathrm{C}$ overnight. In order to assess the regeneration and reusability of the PAN-10 nanofibers, consecutive adsorption-desorption cycles were repeated four times. The adsorption tests were carried out with a $10 \mathrm{mM} \mathrm{KCl}$ solution at $25{ }^{\circ} \mathrm{C}$ for $24 \mathrm{~h}$.

\section{Results and discussion}

\section{Morphology of composite electrospun fibers}

The properties of the electrospun nanofiber formed, in particular the fiber diameter and morphology, depend on various parameters that can be divided into three groups: polymer solution properties, processing conditions and ambient conditions. In this study, processing (applied voltage, volume flow rate) and ambient conditions (temperature, humidity) were held constant in order to systematically investigate the effect of polymer solution properties (crown ether concentration) on the mean fiber diameter. Suspending the DB18C6 in the polymer solution and ensuring the formation of homogenous stable suspensions prior to electrospinning are the frontline challenges in the electrospinning process. Completely transparent
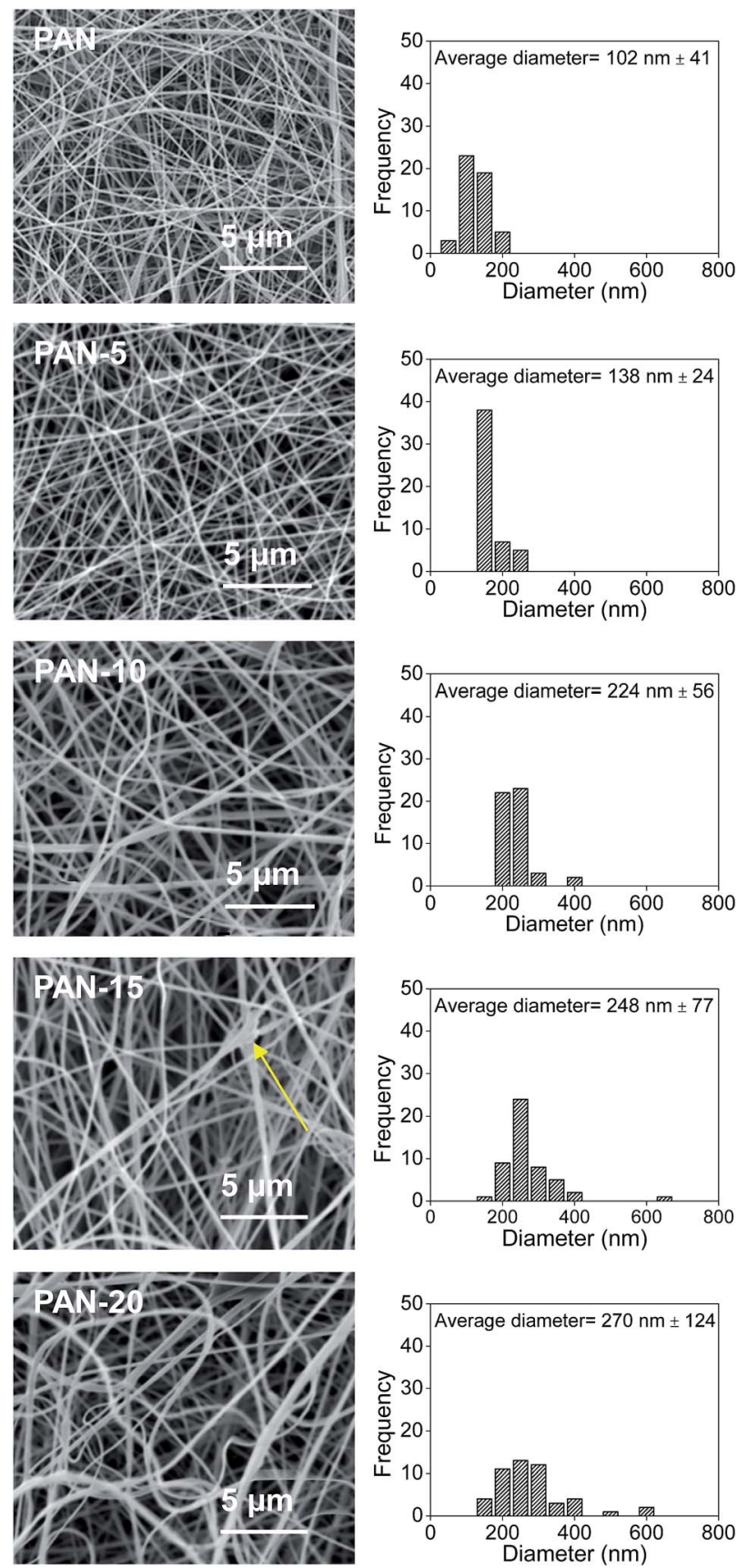

Fig. 3 The morphology and fiber diameter distribution of PAN and PAN/crown ether electrospun nanofibers.

solutions that are stable over a long term were achieved without using any surfactants. Morphologies of the neat and crown ether modified PAN nanofiber mats were characterized by SEM and the micrographs are shown in Fig. 3. The diameter distribution of the nanofibers is also presented in Fig. 3. In these pictures, the DB18C6 concentration was varied while the voltage was kept constant at $15 \mathrm{kV}$ at a constant collector distance of $15 \mathrm{~cm}$. Without the addition of DB18C6, neat PAN nanofibers have a diameter of $102 \pm 41 \mathrm{~nm}$, which is comparable with the values reported in literature. ${ }^{35}$ PAN-5, PAN-10, PAN-15, and PAN-20 nanofibers have mean diameters of $138 \pm 24 \mathrm{~nm}$, 
$224 \pm 56 \mathrm{~nm}, 248 \pm 77 \mathrm{~nm}$, and $270 \pm 124 \mathrm{~nm}$, respectively. The mean fiber diameter increased with DB18C6 concentration, while variance in the fiber diameter was also elevated. The effect on the fiber radii upon addition of crown ether is attributed to two factors: electrical conductivity and rheological changes in the polymer solution. These two contributions have opposing effects on the mean fiber diameter. For instance, the increase of electrical conductivity of a polymer solution leads to thinner fibers, while the fiber diameter tends to increase with shear viscosity. ${ }^{36,37}$ As anticipated, the addition of nonconductive DB18C6 will not increase the electrical conductivity of the solutions $\left(\sigma_{\text {ethanol }}=1.5 \pm 0.1 \mu \mathrm{S} \mathrm{cm}{ }^{-1}\right.$ and $\sigma_{0.1}$ wt $\%$ crown ether/ ethanol $\left.=1.8 \pm 0.2 \mu \mathrm{S} \mathrm{cm}^{-1}\right)$, while the shear viscosity of PAN-5, PAN-10, PAN-15, and PAN-20 solutions increased with the crown ether concentration. Fig. 3 shows that the mean fiber diameter tends to increase with the crown ether/PAN stochastic ratio. Also, increasing crown ether concentrations lead to the formation of bead-like structures (yellow arrow in Fig. 3, (PAN-15)) and a higher variance in the fiber diameter. The mean fiber diameter distribution of PAN and PAN-5 is rather uniform. However, PAN-10, PAN-15 and PAN-20 nanofibers have a broader fiber diameter distribution and comparatively high diameter range from 120 to $650 \mathrm{~nm}$. We assume that the increased viscosity due to the higher crown ether fractions ${ }^{33}$ and the reduced solution conductivity are the primary reason of fiber thickening.

\section{FTIR}

Fig. 4 shows the FTIR spectra of PAN, PAN-10, and PAN-20 nanofibers. In the spectra, all nanofibers exhibited an absorbance at $2921 \mathrm{~cm}^{-1}$ that can be assigned to the stretching vibration of the $-\mathrm{CH}$ and $-\mathrm{CH}_{2}$ groups. ${ }^{15}$ The peaks at $2242 \mathrm{~cm}^{-1}$ and $1451 \mathrm{~cm}^{-1}$ belong to $-\mathrm{C} \equiv \mathrm{N}$ stretching and $-\mathrm{CH}$ vibration of PAN. ${ }^{15,38}$ The presence of crown ether at the PAN surface is confirmed by an absorption peak at $1505 \mathrm{~cm}^{-1}$ that is ascribed to the $-\mathrm{CH}$ stretching vibrations of the alkanes in the aromatic ring of the crown ether. ${ }^{39}$ Moreover, the characteristic $\mathrm{C}-\mathrm{O}-\mathrm{C}$ stretching signals of the crown ethers are observed at around $1060 \mathrm{~cm}^{-1}$ and $1129 \mathrm{~cm}^{-1}$ (ref. 39 and 40) for all PAN/crown ether fibers, while these are absent for neat PAN fibers.

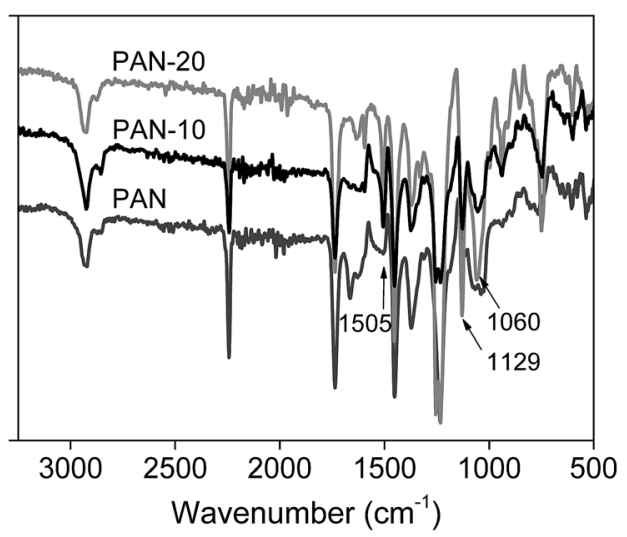

Fig. 4 FTIR spectra of PAN and PAN/crown ether nanofibers.

\section{TGA}

TGA was conducted in order to determine the thermal stability of the nanofibers. Fig. 5 shows the thermogravimetric curves of PAN and PAN/crown ether nanofibers. The removal of residual DMF from the PAN-5 nanofibers causes a slight weight loss around $\sim 150{ }^{\circ} \mathrm{C}$, thus shifting the full curve to a bit lower values. PAN decomposition starts around $335{ }^{\circ} \mathrm{C}$ with the cyclization of the nitrile groups and the decomposition reaction of PAN. ${ }^{41,42}$

PAN-5, PAN-10, PAN-15, and PAN-20 nanofibers exhibit a two-stage thermal degradation profile. The first weight loss results from the removal of the crown ether around $250{ }^{\circ} \mathrm{C} .4^{\mathbf{4 3 4 4}}$ The crown ether is more sensitive to thermal degradation and starts to decompose at around $250{ }^{\circ} \mathrm{C}$. ${ }^{44}$ The decomposition of crown ether is followed by thermal cleavage of PAN at around $350{ }^{\circ} \mathrm{C}$.

\section{Single ion adsorption}

The ion adsorption potential of the developed fibers was investigated for both single and mixed aqueous ion solutions. First, the effect of the adsorption time on the static adsorption capacity of single ions on neat PAN and PAN/crown ether nanofibers was investigated. Fig. 6 shows the results of the adsorption of $\mathrm{Li}^{+}, \mathrm{Na}^{+}, \mathrm{K}^{+}$and $\mathrm{Ba}^{2+}$ ions. Neat PAN nanofibers have almost no adsorption capacity for $\mathrm{Li}^{+}, \mathrm{Na}^{+}, \mathrm{K}^{+}$and $\mathrm{Ba}^{2+}$ ions, whereas PAN/crown ether fibers have a tendency to $\mathrm{Li}^{+}$, $\mathrm{Na}^{+}, \mathrm{K}^{+}$and $\mathrm{Ba}^{2+}$ ion uptake. This leads to the conclusion that the crown ether moieties, which are known to be able to form a complex with the ions, are responsible for the adsorption capacity of the prepared PAN/crown ether nanofibers. ${ }^{22,45,46}$ The adsorption capacity increases over time and levels off after $8 \mathrm{~h}$, indicating that the adsorption equilibrium is achieved.

Fig. 6 indicates that the adsorption capacity for $\mathrm{K}^{+}$ions is higher than that for $\mathrm{Li}^{+}, \mathrm{Na}^{+}$, and $\mathrm{Ba}^{2+}$ ions due to the selective complexation ability of the crown ether with $\mathrm{K}^{+}$ions. ${ }^{47,48} \mathrm{PAN}-10$ and PAN-20 nanofibers exhibit a $\mathrm{K}^{+}$adsorption capacity of $0.37 \mathrm{mmol} \mathrm{g}^{-1}$, which is slightly higher than that of PAN-15 nanofibers $\left(0.34 \mathrm{mmol} \mathrm{g}^{-1}\right)$. The $\mathrm{K}^{+}$uptake increases with

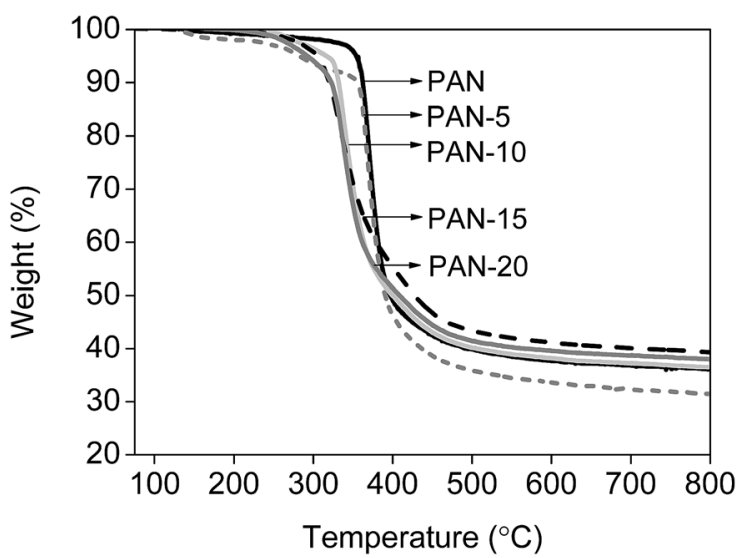

Fig. 5 Thermogravimetric curves of PAN and PAN/crown ether nanofibers. 

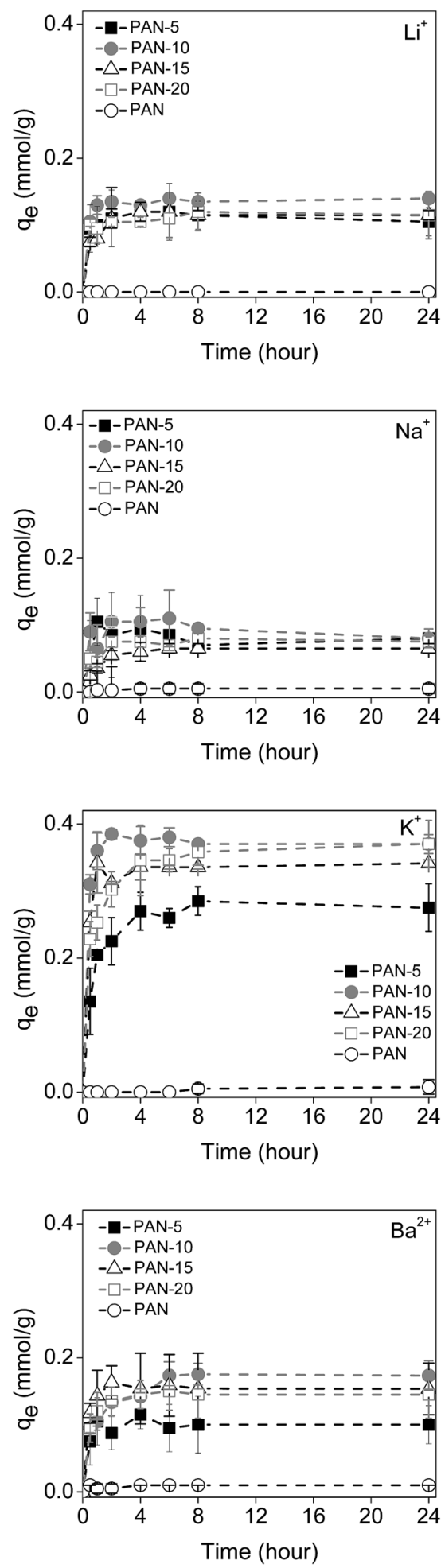

Fig. 6 Adsorption kinetics of $\mathrm{Li}^{+}, \mathrm{Na}^{+}, \mathrm{K}^{+}$and $\mathrm{Ba}^{2+}$ onto PAN and PAN/ crown ether nanofibers.

crown ether concentration, up to $10 \mathrm{wt} \%$, and remains nearly constant with a further increase in crown ether addition. This is expected because higher crown ether loading results in a higher number of available binding sites for the ions. However, this only accounts till a maximum of approximately $10 \mathrm{wt} \%$ crown ether. Beyond this point, a further increase of the crown ether concentration does not have a significant effect on the ion adsorption capacity. Presumably, some of the binding sites are not accessible due to crown ether aggregation. Another reason might be that a fraction of the crown ether is embedded in or covered by the PAN polymer, preventing the binding sites from being freely accessible to the $\mathrm{K}^{+}$ions.

The $\mathrm{Ba}^{2+}$ adsorption capacities obtained with PAN-5, PAN10, PAN-15, and PAN-20 nanofibers are $0.10 \mathrm{mmol} \mathrm{g}^{-1}, 0.17$ $\mathrm{mmol} \mathrm{g}^{-1}, 0.15 \mathrm{mmol} \mathrm{g}^{-1}$, and $0.15 \mathrm{mmol} \mathrm{g}^{-1}$, respectively and the capacities are in all cases lower than the $\mathrm{K}^{+}$ion adsorption capacity. Takeda et al. investigated benzo-18-crown-6-metal complex formation constants in water by conductometry or potentiometry and spectrophotometry, respectively. They found a selectivity sequence of $\mathrm{Ba}^{2+}>\mathrm{K}^{+}>\mathrm{Na}^{+}{ }^{49}$ Shchori et al. determined the aqueous stability constants for complex formation of DB18C6 with $\mathrm{Li}^{+}, \mathrm{Na}^{+}, \mathrm{K}^{+}$and $\mathrm{Ba}^{2+}$. In this case, $\mathrm{K}^{+}$and monodissociated ion pairs $[\mathrm{BaCl}]^{+}$complex more strongly with DB18C6 compared to $\mathrm{Li}^{+}$and $\mathrm{Na}^{+}{ }^{+50}$ Although the previous researches demonstrate a strong affinity between DB18C6 and $\mathrm{Ba}^{2+}$, we observe higher $\mathrm{K}^{+}$ion uptakes by the PAN/crown ether nanofibers. We will come back to this issue while discussing the mixed ion adsorption results.

The $\mathrm{Na}^{+}$and $\mathrm{Li}^{+}$ion adsorption capacities are the lowest of all ions investigated. In both cases, the adsorbed amount is almost the same and hardly changes with an increase of the crown ether mass fraction. We reason that, due to weak interactions between $\mathrm{Na}^{+}$and $\mathrm{Li}^{+}$ions and DB18C6, the adsorption capacity of the crown ether for these ions is lower and less stable complexes are formed in which the ions can easily dissociate from the crown ether. ${ }^{51}$

\section{XPS spectra}

Elemental analyses of PAN and PAN-10 nanofibers were conducted by XPS in order to investigate the presence and effectiveness of the crown ether upon ion adsorption. The atomic ratios of $\mathrm{C} / \mathrm{O}$ and $\mathrm{C} / \mathrm{N}$ are shown in Table 1 . As expected, we observe a slight $\mathrm{C} / \mathrm{N}$ ratio increase as a result of an increase in the percentage of carbon relative to nitrogen due to the addition of the crown ether.

Fig. 7 exhibits the survey spectrum and the high resolution $\mathrm{C}$ 1s, O 1s spectra of PAN, PAN-10 before and PAN-10 nanofibers after $\mathrm{Ba}^{2+}$ adsorption. The survey XPS spectrum of PAN nanofibers shown in Fig. 7 exhibits two intense peaks at 286.4 and $339.5 \mathrm{eV}$ corresponding to $\mathrm{C} 1 \mathrm{~s}$ and $\mathrm{N} 1 \mathrm{~s}$ core levels, respectively. In addition to those peaks, we also observe a water induced $\mathrm{O} 1 \mathrm{~s}$ peak centered at $533.03 \mathrm{eV}^{52}$ The $\mathrm{C} 1 \mathrm{~s}$ core spectra of PAN can be cure-fitted to three peaks. The peaks at $286.74,285.84$ and $284.94 \mathrm{eV}$ belong to

Table 1 Atomic ratios of $\mathrm{C} / \mathrm{O}$ and $\mathrm{C} / \mathrm{N}$ for neat PAN and PAN-10 nanofibers

\begin{tabular}{lcc}
\hline & $\mathrm{C} / \mathrm{O}$ & $\mathrm{C} / \mathrm{N}$ \\
\hline PAN & 21.0 & 3.6 \\
PAN-10 & 16.3 & 4.0
\end{tabular}



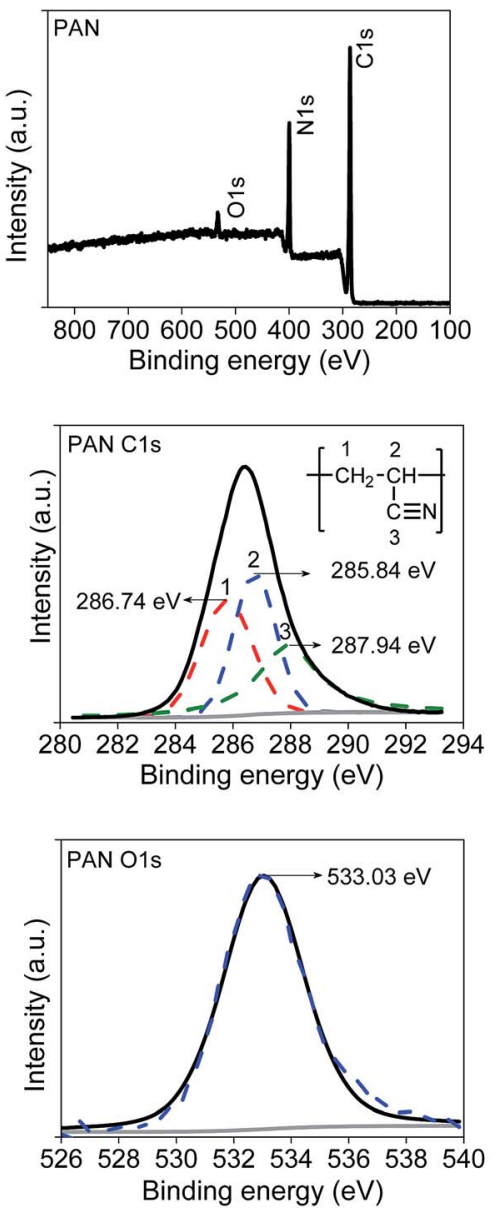
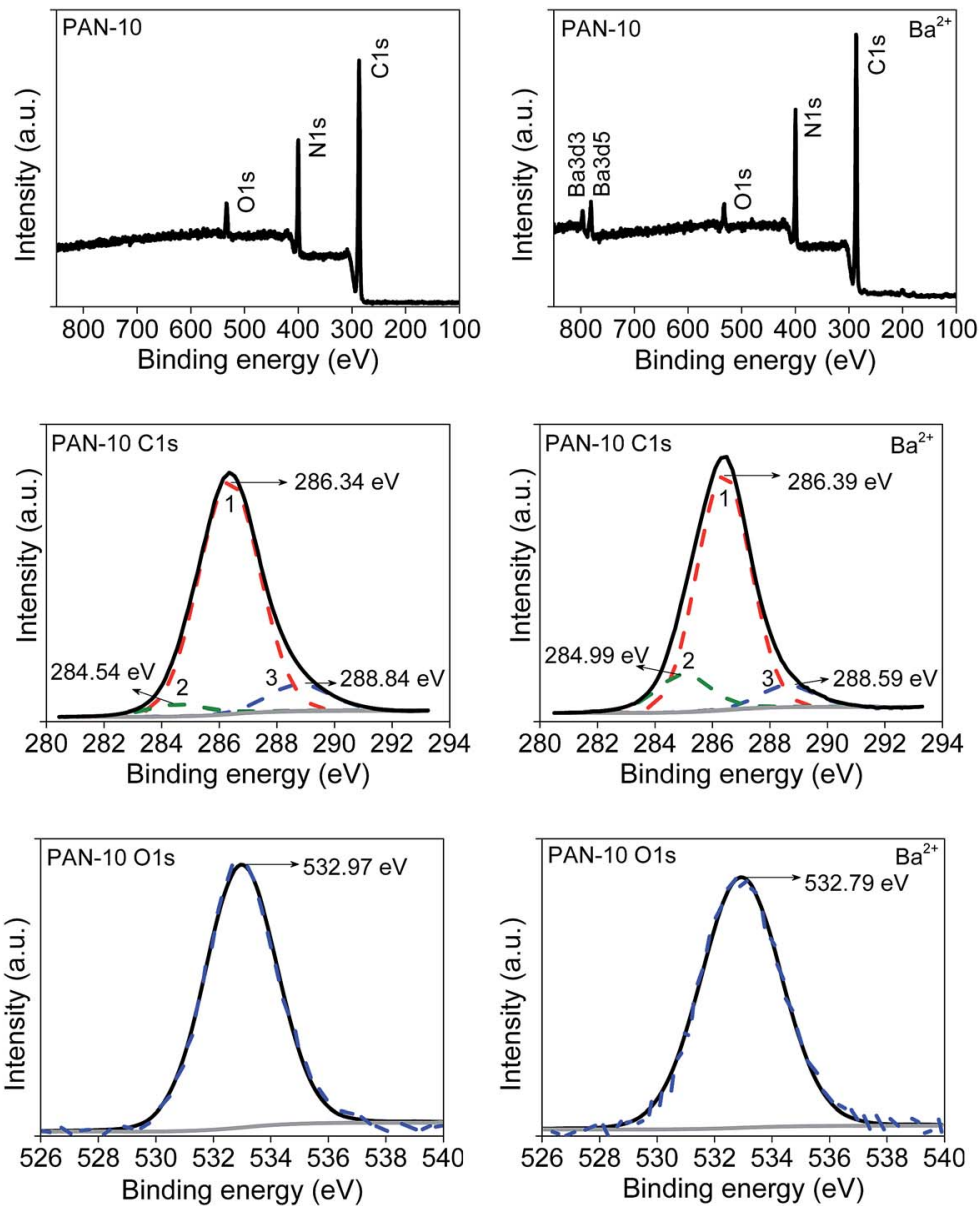

Fig. 7 XPS survey and high resolution XPS spectra of $C 1$ s, $O 1$ s of PAN, PAN-10 and PAN-10-B.

the $-\mathrm{CH}_{2},-\mathrm{CH}-\mathrm{CN}$ and $-\mathrm{C} \equiv \mathrm{N}$ groups, respectively. The peak areas of the functional groups of $-\mathrm{CH}_{2},-\mathrm{CH}-\mathrm{CN}$ and $-\mathrm{C} \equiv \mathrm{N}$ are equal to each other. ${ }^{53,54}$ The survey spectrum of PAN-10 shown in Fig. 7 also shows the peaks of the $\mathrm{C} 1 \mathrm{~s}, \mathrm{~N} 1 \mathrm{~s}$, and $\mathrm{O} 1 \mathrm{~s}$ core levels. Comparison of the PAN-10 C 1s spectra with those of PAN shows a peak shift. The relative peak intensities of the peaks change upon crown ether addition, and the peak at 286.34 becomes more intense compared to the other two peaks. The peak at $286.34 \mathrm{eV}$ reflects the presence of ether carbon. ${ }^{55,56}$ The $\mathrm{O}$ 1s spectrum of PAN-10 has one peak, similar to that of PAN. However, the peak shifts to a slightly lower binding energy, which is in good agreement with the previously reported $O$ 1s spectra of the native crown ether. ${ }^{57}$ Finally, the spectra for PAN-10 nanofibers after barium adsorption clearly show the oxidation states of the barium ions.

The $\mathrm{O} 1 \mathrm{~s}$ peak appears again at $532.79 \mathrm{eV}$, and no significant chemical shift in $\mathrm{O}$ 1s peak is observed after complexation of the crown ether with $\mathrm{Ba}^{2+}$ ions. The two peaks at 795.3 and 780.5 $\mathrm{eV}$ correspond to the $\mathrm{Ba} 3 \mathrm{~d}_{3 / 2}$ and $\mathrm{Ba} 3 \mathrm{~d}_{5 / 2}$ binding energies respectively ${ }^{58,59}$ and confirm the adsorption of the $\mathrm{Ba}^{2+}$ ions on the PAN/crown ether nanofiber.

\section{Mixed ion adsorption}

Competitive adsorption experiments are carried out in order to assess the selective and competitive recognition of the crown ether modified PAN nanofibers for specific ions. Fig. 8 shows the adsorption capacities of PAN, PAN-5, PAN-10, PAN-15, and PAN-20 nanofibers for a mixture of $\mathrm{Li}^{+}, \mathrm{Na}^{+}, \mathrm{K}^{+}$and $\mathrm{Ba}^{2+}$ ions.

Neat PAN nanofibers exhibit no adsorption capacity for $\mathrm{Na}^{+}$ and $\mathrm{Li}^{+}$ions and only very small capacities for $\mathrm{K}^{+}$and $\mathrm{Ba}^{2+}$ ions. Single ion experiments showed that the PAN/crown ether nanofibers exhibited the highest adsorption capacities for $\mathrm{K}^{+}$ ions compared to the other ions. The same behavior is observed for $\mathrm{K}^{+}$over $\mathrm{Li}^{+}$and $\mathrm{Na}^{+}$. The developed nanofibers can be used to

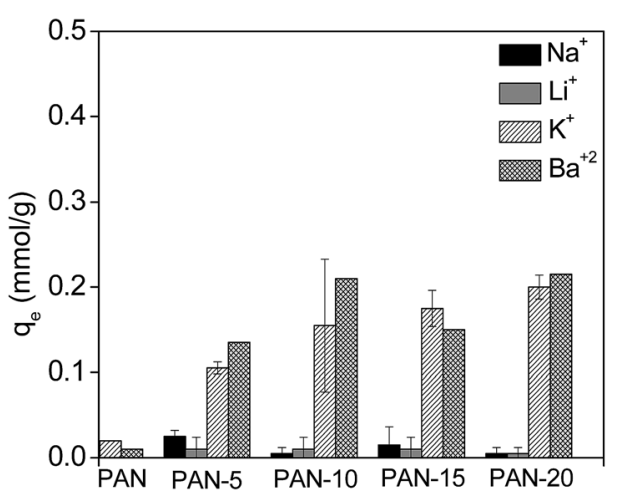

Fig. 8 Adsorption capacities of neat PAN and PAN/crown ether nanofibers for mixed ion systems. 
separate selectively $\mathrm{K}^{+}$from $\mathrm{Li}^{+}$and $\mathrm{Na}^{+}$ions. The presence of $\mathrm{Ba}^{2+}$ ions in the mixture, however, shows a different behavior. $\mathrm{Ba}^{2+}$ and $\mathrm{K}^{+}$ion adsorption capacities are fairly equal in mixed ion adsorption measurements. Moreover, as Fig. 8 reveals, the $\mathrm{Ba}^{2+}$ ion adsorption capacities are more or less equal to their single ion equivalents, while the $\mathrm{K}^{+}$adsorption is significantly reduced when $\mathrm{Ba}^{2+}$ is present in the solution. As we mentioned before, DB18C6 can form stable complexes with $\mathrm{K}^{+}$and $\mathrm{Ba}^{2+}$ ions, and therefore competition exists between $\mathrm{K}^{+}$and $\mathrm{Ba}^{2+}$ ions for the available binding sites. ${ }^{49,50}$ Among the metal ions, $\mathrm{Na}^{+}$ and $\mathrm{Li}^{+}$have the weakest ability to bind to the PAN-10 nanofibers.

Table 2 presents the adsorption selectivities of the different cationic species for the different crown ether concentrations in the PAN fibers. Selectivities calculated based on both single and mixed ion adsorptions are shown. Table 2 shows the $\mathrm{K}^{+} / \mathrm{Li}^{+}$, $\mathrm{K}^{+} / \mathrm{Na}^{+}$and $\mathrm{K}^{+} / \mathrm{Ba}^{2+}$ adsorption selectivity coefficients of PAN/ crown ether nanofibers for single ion and mixed ion adsorption experiments. For single ion experiments, increasing the crown ether mass fraction does not significantly affect the $\mathrm{K}^{+}$/ $\mathrm{Li}^{+}, \mathrm{K}^{+} / \mathrm{Na}^{+}$, and $\mathrm{K}^{+} / \mathrm{Ba}^{2+}$ adsorption selectivities. The crown ether fibers seem to exhibit a slightly higher selectivity for $\mathrm{K}^{+}$ over $\mathrm{Na}^{+}$than for the other ions, but still selectivities are low. When mixtures are considered, the behavior changes drastically. Selectivities for $\mathrm{K}^{+}$over especially $\mathrm{Li}^{+}$but also $\mathrm{Na}^{+}$significantly increase, while the selectivity for $\mathrm{K}^{+}$over $\mathrm{Ba}^{2+}$ decreases due to competition for the binding sites. So in the case of $\mathrm{Li}^{+}$ and $\mathrm{Na}^{+}$, competition is for the benefit of $\mathrm{K}^{+}$, while this switches when $\mathrm{Ba}^{2+}$ is present. In that case, $\mathrm{Ba}^{2+}$ is preferentially adsorbed. This is due to the preference of the crown ether for $\mathrm{Ba}^{2+}$ over $\mathrm{K}^{+}$, as also observed in literature. ${ }^{49,50}$ These results clearly show exceptionally high $\mathrm{K}^{+}$over $\mathrm{Li}^{+}$and $\mathrm{Na}^{+}$selectivities, making the developed fibers very attractive for the selective recovery of $\mathrm{K}^{+}$from mixtures with other monovalent ions. One exception is the selectivity for $\mathrm{K}^{+}$over $\mathrm{Na}^{+}$for the PAN-15 fibers. There the selectivity unexpectedly drops. We do not have a clear explanation for that, but expect this is due to an artefact. In addition, also the errors in the mixed $\mathrm{K}^{+} / \mathrm{Na}^{+}$selectivities for the other fibers are relatively large in case of mixtures.

\section{Reusability of nanofibers}

Effective regeneration of the nanofibers is essential for their potential application as an adsorbent for the selective recovery of ions from aqueous solutions. Therefore, we investigated the $\mathrm{K}^{+}$adsorption onto PAN-10 nanofibers, and the subsequent

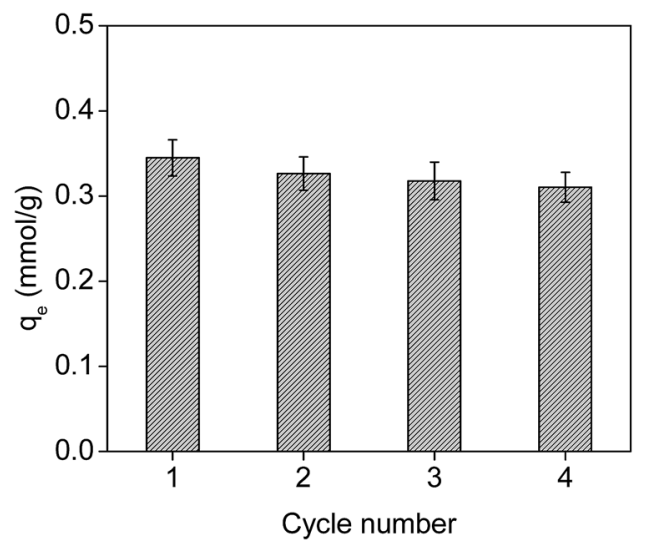

Fig. $9 \mathrm{~K}^{+}$adsorption capacity of PAN/crown ether (PAN-10) nanofibers as a function of the number of adsorption-desorption.

regeneration of the $\mathrm{K}^{+}$loaded PAN-10 nanofibers. Desorption tests were performed with $1 \mathrm{M} \mathrm{HCl}$, and the regenerated fibers were used for in total 4 adsorption-desorption cycles. The results are shown in Fig. 9. Fig. 9 shows a slight capacity loss of only $10 \%$ after the first 2 adsorption-desorption cycles, but overall, the adsorption capacity remains rather constant after that. This small loss is most probably due to the fact that not all $\mathrm{K}^{+}$ions could desorbed with $1 \mathrm{M} \mathrm{HCl}$ and some small amounts remain adsorbed.

\section{Conclusions}

PAN/crown ether nanofiber mats containing different weight fractions of the crown ether DB18C6 were prepared by electrospinning. FTIR confirmed the presence of the crown ether in the PAN nanofiber matrix. SEM microscopy images showed that the addition of crown ether resulted in thicker nanofibers. The average diameter of the PAN nanofibers increased from $102 \mathrm{~nm}$ to $270 \mathrm{~nm}$ with the addition of $20 \mathrm{wt} \%$ crown ether with respect to PAN. Single ion adsorption results revealed a selectivity sequence of $\mathrm{K}^{+}>\mathrm{Ba}^{2+}>\mathrm{Na}^{+} \sim \mathrm{Li}^{+}$for DB18C6 modified PAN nanofibers. In mixed salt solutions the adsorption capacity of $\mathrm{K}^{+}$ ion declined in the presence of especially $\mathrm{Ba}^{2+}$ ions suggesting competition between the ions for the available binding sites. The PAN/crown ether nanofibers exhibit exceptionally high selectivities for $\mathrm{K}^{+}$over $\mathrm{Li}^{+}$and $\mathrm{Na}^{+}$. Considering reusability, PAN/crown ether nanofibers only lose $10 \%$ of the $\mathrm{K}^{+}$adsorption capacity after four consecutive adsorption and desorption

Table 2 Adsorption selectivities of PAN/crown ether nanofibers

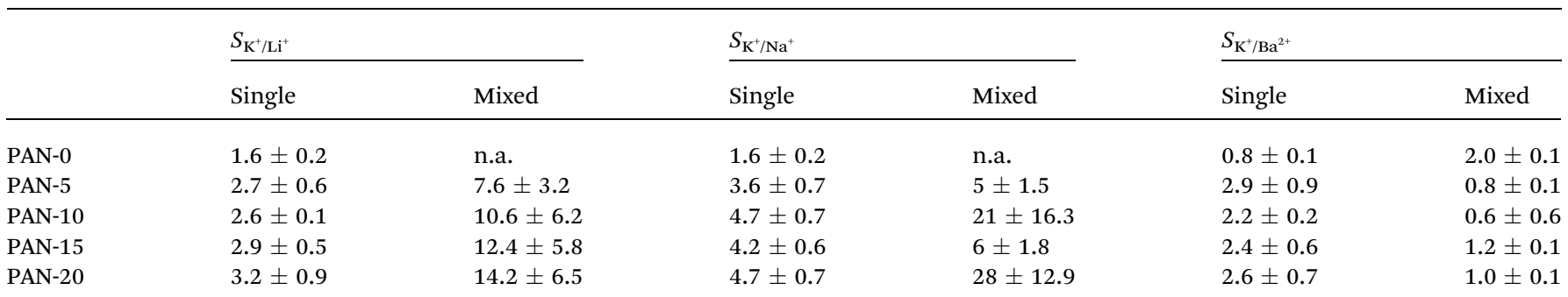


cycles. Electrospinning thus shows to be a very versatile tool to prepare crown ether functional polymer adsorbents.

\section{Acknowledgements}

Sinem Tas acknowledges the Industrial Partnership Program (IPP) "Spectroscopic analysis of particles in water" of the Stichting voor Fundamenteel Onderzoek der Materie (FOM), which is financially supported by the Nederlandse Organisatie voor Wetenschappelijk Onderzoek (NWO). This IPP is cofinanced by Wetsus, Centre of Excellence for Sustainable Water Technology, as part of Wetsus' TTI program. Wetsus is co-funded by the Dutch ministry of economics, agriculture and innovation. Elif Ozden-Yenigun acknowledges İTÜ-BAP (Grant number: 38227).

\section{References}

1 N. Bhardwaj and S. C. Kundu, Biotechnol. Adv., 2010, 28, 325347.

2 C. X. Zhang, X. Y. Yuan, L. L. Wu, Y. Han and J. Sheng, Eur. Polym. J., 2005, 41, 423-432.

3 J. D. Schiffman and C. L. Schauer, Polym. Rev., 2008, 48, 317352.

4 J. P. Canejo, J. P. Borges, M. H. Godinho, P. Brogueira, P. I. C. Teixeira and E. M. Terentjev, Adv. Mater., 2008, 20, 4821-4825.

5 A. Baji, Y. W. Mai, S. C. Wong, M. Abtahi and P. Chen, Compos. Sci. Technol., 2010, 70, 703-718.

6 K. M. Yun, C. J. Hogan, Y. Mastubayashi, M. Kawabe, F. Iskandar and K. Okuyama, Chem. Eng. Sci., 2007, 62, 4751-4759.

7 R. Gopal, S. Kaur, Z. W. Ma, C. Chan, S. Ramakrishna and T. Matsuura, J. Membr. Sci., 2006, 281, 581-586.

8 S. S. Homaeigohar, K. Buhr and K. Ebert, J. Membr. Sci., 2010, 365, 68-77.

9 T. Tamura and H. Kawakami, Nano Lett., 2010, 10, 13241328.

10 I. Shabani, M. M. Hasani-Sadrabadi, V. Haddadi-Asl and M. Soleimani, J. Membr. Sci., 2011, 368, 233-240.

11 T. J. Sill and H. A. von Recum, Biomaterials, 2008, 29, 19892006.

12 M. Gorji, A. A. A. Jeddi and A. A. Gharehaghaji, J. Appl. Polym. Sci., 2012, 125, 4135-4141.

13 S. Lee, Fibers Polym., 2009, 10, 295-301.

14 X. Yan, M. Zhou, J. Chen, X. Chi, S. Dong, M. Zhang, X. Ding, Y. Yu, S. Shao and F. Huang, Chem. Commun., 2011, 47, 7086-7088.

15 M. Chen, C. J. Wang, W. Fang, J. Wang, W. Zhang, G. Jin and G. W. Diao, Langmuir, 2013, 29, 11858-11867.

16 A. Celebioglu, S. Demirci and T. Uyar, Appl. Surf. Sci., 2014, 305, 581-588.

17 F. Kayaci, Z. Aytac and T. Uyar, J. Hazard. Mater., 2013, 261, 286-294.

18 G. S. Hong, M. Wang, X. Li, L. D. Shen, X. F. Wang, M. F. Zhu and B. S. Hsiao, RSC Adv., 2015, 5, 21178-21188.
19 M. Bayrakc1, F. Özcan and Ş. Ertul, Tetrahedron, 2015, 71, 3404-3410.

20 M. Nogami, T. Haratani, Y. Tachibana, T. Kaneshiki, M. Nomura and T. Suzuki, J. Radioanal. Nucl. Chem., 2015, 303, 1549-1553.

21 K. J. Hintze, A. Lutzen and T. Bredow, J. Comput. Chem., 2015, 36, 1467-1472.

22 U. Tunca and Y. Yagci, Prog. Polym. Sci., 1994, 19, 233-286.

23 S. D. Alexandratos and C. L. Stine, React. Funct. Polym., 2004, 60, 3-16.

24 X. Z. Yan, T. R. Cook, J. B. Pollock, P. F. Wei, Y. Y. Zhang, Y. H. Yu, F. H. Huang and P. J. Stang, J. Am. Chem. Soc., 2014, 136, 4460-4463.

25 O. Duman and E. Ayranci, J. Hazard. Mater., 2010, 176, 231238.

26 R. E. C. Torrejos, G. M. Nisola, M. J. Park, H. K. Shon, J. G. Seo, S. Koo and W. J. Chung, Chem. Eng. J., 2015, 264, 89-98.

27 X. J. Ju, S. B. Zhang, M. Y. Zhou, R. Xie, L. Yang and L. Y. Chu, J. Hazard. Mater., 2009, 167, 114-118.

28 X. B. Luo, B. Guo, J. M. Luo, F. Deng, S. Y. Zhang, S. L. Luo and J. Crittenden, ACS Sustainable Chem. Eng., 2015, 3, 460-467.

29 H. R. Rajabi, M. Shamsipur and S. M. Pourmortazavi, Mater. Sci. Eng., C, 2013, 33, 3374-3381.

30 X. B. Luo, L. L. Liu, F. Deng and S. L. Luo, J. Mater. Chem. A, 2013, 1, 8280-8286.

31 D. A. Musale, A. Kumar and G. Pleizier, J. Membr. Sci., 1999, 154, 163-173.

32 D. A. Musale and A. Kumar, J. Appl. Polym. Sci., 2000, 77, 1782-1793.

33 T. Wang and S. Kumar, J. Appl. Polym. Sci., 2006, 102, 10231029.

34 G. Y. H. Soo Jin Park, in Carbon Fibers, Springer, The Netherlands, 2015, vol. 210, ch. Precursors and Manufacturing of Carbon Fibers, pp. 31-66.

35 O. S. Yördem, M. Papila and Y. Z. Menceloğlu, Mater. Des., 2008, 29, 34-44.

36 J. M. Deitzel, J. Kleinmeyer, D. Harris and N. C. B. Tan, Polymer, 2001, 42, 261-272.

37 E. Ozden-Yenigun, Y. Z. Menceloglu and M. Papila, ACS Appl. Mater. Interfaces, 2012, 4, 777-784.

38 C. Q. Zhang, Q. B. Yang, N. Q. Zhan, L. Sun, H. G. Wang, Y. Song and Y. X. Li, Colloids Surf., A, 2010, 362, 58-64.

39 H. Zhu, M. L. Du, M. L. Zou, C. S. Xu, N. Li and Y. Q. Fu, J. Mater. Chem., 2012, 22, 9301-9307.

40 M. Dulak, R. Bergougnant, K. M. Fromm, H. R. Hagemann, A. Y. Robin and T. A. Wesolowski, Spectrochim. Acta, Part A, 2006, 64, 532-548.

41 Y. Z. Shi, Y. J. Li, J. F. Zhang, Z. Z. Yu and D. Z. Yang, Mater. Sci. Eng., C, 2015, 51, 346-355.

42 N. C. Abeykoon, J. S. Bonso and J. P. Ferraris, RSC Adv., 2015, 5, 19865-19873.

43 S. Gurrieri, A. Seminara, G. Siracusa and A. Cassol, Thermochim. Acta, 1975, 11, 433-439.

44 A. Bhattacharyya and A. Goswami, J. Phys. Chem. B, 2009, 113, 12958-12963. 
45 D. L. Tzeng, J. S. Shih and Y. C. Yeh, Analyst, 1987, 112, 14131416.

46 A. H. Bond, M. L. Dietz and R. Chiarizia, Ind. Eng. Chem. Res., 2000, 39, 3442-3464.

47 P. D. J. Grootenhuis and P. A. Kollman, J. Am. Chem. Soc., 1989, 111, 2152-2158.

48 M. Nakajima, K. Kimura and T. Shono, Bull. Chem. Soc. Jpn., 1983, 56, 3052-3056.

49 Y. Takeda, R. Kohno, Y. Kudo and N. Fukada, Bull. Chem. Soc. Jpn., 1989, 62, 999-1003.

50 E. Shchori, N. Nae and J. Jagurgrodzinski, J. Chem. Soc., Dalton Trans., 1975, 2381-2386, DOI: 10.1039/dt9750002381.

51 S. Maleknia and J. Brodbelt, J. Am. Chem. Soc., 1993, 115, 2837-2843.

52 M. Abu Haija, S. Guimond, A. Uhl, H. Kuhlenbeck and H. J. Freund, Surf. Sci., 2006, 600, 1040-1047.
53 L. Li, C. M. Chan and L. T. Weng, Macromolecules, 1997, 30, 3698-3700.

54 D. Briggs and G. Beamson, High Resolution XPS of Organic Polymers: The Scienta ESCA 300 Database, John Wiley and Sons, Chichester, England, New York, 1992.

55 E. E. Johnston, J. D. Bryers and B. D. Ratner, Langmuir, 2005, 21, 870-881.

56 A. L. Vance, T. M. Willey, T. van Buuren, A. J. Nelson, C. Bostedt, G. A. Fox and L. J. Terminello, Nano Lett., 2003, 3, 81-84.

57 T. K. Tran, K. Smaali, M. Hardouin, Q. Bricaud, M. Ocafrain, P. Blanchard, S. Lenfant, S. Godey, J. Roncali and D. Vuillaume, Adv. Mater., 2013, 25, 427-431.

58 B. W. Liu, Y. Zhang and L. D. Tang, Int. J. Hydrogen Energy, 2009, 34, 435-439.

59 H. Vandoveren and J. A. T. Verhoeven, J. Electron Spectrosc. Relat. Phenom., 1980, 21, 265-273. 